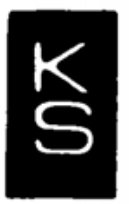



Michael Gaebel ·

Kritik des arabischen Denkens 
ISLAMKUNDLICHE UNTERSUCHUNGEN • BAND 189

\author{
begründet \\ von \\ Klaus Schwarz \\ herausgegeben \\ von \\ Gerd Winkelhane
}


ISLAMKUNDLICHE UNTERSUCHUNGEN • BAND 189

\section{Michael Gaebel}

Von der Kritik des arabischen Denkens zum panarabischen Aufbruch

Das philosophische und politische Denken Muhammad 'Ābid al-Gābirīs 
Die Deutsche Bibliothek - CIP-Einheitsaufnahme

Gaebel, Michael:

Von der Kritik des arabischen Denkens zum panarabischen

Aufbruch : das philosophische und politische Denken

Muhammad 'Ábid al-Gābirìs / Michael Gaebel. - Berlin :

Schwarz, 1995

(Islamkundliche Untersuchungen ; Bd. 189)

ISBN 3-87997-238-9

NE: GT

Alle Rechte vorbehalten.

Ohne ausdrückliche Genehmigung des Verlages

ist es nicht gestattet, das Werk oder einzelne Teile daraus

nachzudrucken oder zu vervielfältigen.

(c) Gerd Winkelhane, Berlin 1995.

Klaus Schwarz Verlag GmbH, Postfach 4102 40, D-12112 Berlin

ISBN 3-87997-238-9

Druck: Offsetdruckerei Gerhard Weinert GmbH, D-12099 Berlin 
Wolfgang Gaebel zum 60. Geburtstag

\section{Danksagung}

Ich möchte die Gelegenheit nutzen, allen zu danken, die zu dieser Arbeit beigetragen haben.

Mein besonderer Dank gilt Ulrich Münch für die unermüdliche

Lektüre und Diskussion meiner Texte und Hedwig Linden

für Rat und Kritik in entscheidenden Momenten.

Berlin, 20.1.1995

Michael Gaebel 
